\title{
Hospital Preparedness Level and Policy Implementation Analysis of Hospital Disaster Plan in RSUD Kota Yogyakarta
}

\author{
* Belva Prima Geniosa, ** Qurratul Aini \\ **** Master of Hospital Management, Universitas Muhammadiyah Yogyakarta, Jalan Brawijaya, Kasihan, Bantul, \\ Daerah Istimewa Yogyakarta, 55183
}

Email : belvageniosa@gmail.com,

\begin{abstract}
Hospital is a public facility that must continue on full operation when a disaster occurs. In any disaster situation that results in a surge in patients, hospitals are expected to provide health services for the victims. This study uses mixed research methods. We combine qualitative methods using in-depth interviews and quantitative methods using questionnaires and hospital safety index scoring. The sample was taken by purposive sampling on hospitals' management incorporated in the disaster management organization structure. The hospital safety index score result is $62.5 \%$. The knowledge questionnaire results showed $77 \%$ percentage, meaning that the staff's knowledge of disasters was excellent. RSUD Kota Yogyakarta's Hospital Safety Index result means that it is still in category B. This category means that the hospital still has some risks affecting their maximum function in facing disaster.
\end{abstract}

Keywords: coordination, essential drug, management

\section{INTRODUCTION}

Indonesia is a country where almost all of its areas have natural disasters. Data collected by the National Disaster Management Agency in 2016 shows that there are more than 19,000 natural disasters from the period of 2001 to $2015^{1}$.

Hospitals are public facilities that must to continue to operate fully even when a disaster occurs ${ }^{2}$. Hospitals are part of health care providers that have an important role in reducing mortality from disasters. Therefore, a hospital should be built and managed to deal with any crisis effectively ${ }^{3}$. In any disaster situation that results in a surge in patients, hospitals are expected to provide health services for existing victims ${ }^{4}$.

The economy of a country has a vital role in developing disaster management systems to reduce the vulnerability of an area affected by disasters ${ }^{5}$. Given the complexity of this problem, hospitals must invest substantial effort in developing disaster preparedness plans and training while coordinating with the appropriate public health systems and government agencies. For example, the Joint Commission for Accreditation of Health Care Organizations (JCAHO) in the United States has issued a standard that requires hospitals to develop cooperative disaster planning "among health care organizations that, together, provide services to adjacent geographical areas." This standard also requires hospitals to test their emergency management plans twice a year, including at least one practice throughout the community to assess communication, coordination and command structures' effectiveness ${ }^{6}$.

\section{METHODS}

This study is a mixed-method researsch that combines qualitative and quantitative descriptive methods. Qualitative research methods are used to determine the implementation of disaster management policies in hospitals by in-depth interviews. Quantitative methods are used to determine the level of hospital preparedness for disasters assessed based on the disaster management and hazard index. The use of mixed methods in this study is intended to provide more comprehensive facts on the problems and answer questions that cannot be done by one method alone.

The subjects in this study were employees in the disaster management command system in Yogyakarta City Hospital. The research object is the existing condition of disaster preparedness in Yogyakarta City Hospital system.

We use the purposive sampling method, in which members of the population were chosen with certain considerations to answer the research question. The population of the study was all of the management staff of Yogyakarta City Hospital. The sample chosen from 
the population is determined based on their position in the disaster management command system, job description in the system and willingness to be a research sample. The inclusion criteria were staff who works for more than one year of work time in Yogyakarta City Hospital. In this study, the exclusion criteria were employees who were on leave and employees who were unwilling to become respondents.

The research instruments used were WHO 2015 Hospital Safety Index, disaster knowledge questionnaire, interview questions, and interview recording equipment. The techniques of collecting data are by interview, direct observation, and document assessment.

Collected data will be analyzed using parallel or concurrent design. Quantitative and qualitative data analysis were done simultaneously and analyzed independently according to their respective designs. We then analyzed the data by connecting and comparing the results of quantitative and qualitative data analysis, and providing interpretations.

Quantitative analysis uses deductive approaches, from the determination of variables (concepts) and data collection. On the other hand, the qualitative method uses inductive approaches. The research process begins with detailing data regarding the topic or research problem, without evaluation and interpretation, then categorize each themes, concept or theory.

\section{RESULTS}

1. Disaster Management Policy in Yogyakarta City Hospital

The hospital already has a disaster management team divided into two: JHERT (Jogja Hospital Emergency Response Team) as a rapid reaction team and $\mathrm{K} 3$ Division (Occupational Safety and Health) as a disaster mitigation team. The JHERT team has the main task of leading disaster management assisted by hospital staff appointed according to the JHERT coordinator's checklist. Disaster management activities were setting the level of alert, coordinating each hospital element, and communicating and coordinating with other disaster management agencies.

\section{Level of Disaster Preparedness in Yogyakarta City Hospital}

This study uses a combined method of qualitative and quantitative. For quantitative method, we used the fourth module of WHO Safety Index form from 2015, the Emergency and Disaster Management module. This module has assessment items related to disaster documents and also points to hospital disaster preparedness management.
We retrieved data from field observations and interviews regarding the availability of the disaster documents. The results of these observations were stratified based on the level of danger, divided into low, medium, and high. Then we give scores to each level, such as 0 for the low level, 0,5 for the medium level, and 1 for the high level. The level determination is also regulated in the HIS form by WHO and different items.. The result percentage is $62.5 \%$. Therefore, making Yogyakarta City Hospital as a category B hospital, between $36-65 \%$. This result means that if a disaster occurs, the hospital still has obstacles to do its functions optimally.

3. Knowledge of Disaster Management Employees at Yogyakarta City Hospital

The data were retrieved from the knowledge questionnaires to 30 respondents. The average knowledge results are $77 \%$. Based on the grouping by Arikunto (2002), a good cognitive knowledge of disaster management is $76-100 \%, 56-75 \%$ is average, and $<55 \%$ is bad. Thus, the Yogyakarta City Hospital staff have a good knowledge of disaster management.

\section{DISCUSSION}

1. Disaster Management Policy in Yogyakarta City Hospital

Hospitals are the community's main hope when a disaster occurs that threatens many people's lives and health, such as expected protection in the form of medical care for the injured and safe location to survive during a disaster ${ }^{7}$. Disaster preparedness systems are the main key to hospitals' success in overcoming mass casualties or other emergencies ${ }^{8}$.

Coordination between hospitals, volunteers, employees, and other parties related to the disaster needs to be carried out both during a disaster and when a disaster is declared completed ${ }^{9}$. The existing coordination system should be examined annually with simulations involving all relevant parties. This evalution is needed so that the running system is always tested and ready when a disaster occurs ${ }^{10}$.

In each disaster management plan, a responsible person should been assigned and has various job descriptions ${ }^{11}$. There are no rules that requires the director to be the incident commander during a disaster. The team director from Yogyakarta City Hospital is the person in charge, but the incident commander's position is held by medical service sector's deputy director. The position will be active when the director determines the state of the disaster and will be stop when the disaster is deactivated. These are the interviews with the following respondents regarding the existence of JHERT (Jogja Hospital Emergency Response Team) and K3 
(Occupational Safety and Health):

"This hospital has two teams that play big roles during the disaster mitigation: JHERT as the field team, while the K3 team as a policy maker and trainer for the JHERT team."

The primary human resources present during a disaster are medical staff, including doctors and nurses. However, it cannot be denied that hospital resources must also be affected by the disaster. Thus, the staff who work on-call is needed to be present by the hospital. Essential human resources that should be present during disasters are orthopedic surgeons, anesthetists, obstetrics and gynecology doctors, and emergency doctors (emergency specialists). They are needed to be present because most cases when a disaster is a case of trauma. Nevertheless, when entering the recovery phase, the leading human resources are psychologists, physiotherapists, pediatricians, obstetricians and gynecologists, and other support staff ${ }^{12}$.

The Yogyakarta city general hospital already has specialist doctors, and medical support staff needed. However, setting a schedule that applies when a disaster does not yet exist, because the staff fear that they cannot perform their duties optimally in the event of a disaster. After having a perfect system, some factors can cause the failure of disaster management. These factors include the cessation of electricity supply due to infrastructure damage, lack of clean water supply due to damage to hospital water tanks, and various damage caused by most infrastructure. In addition to infrastructure, failure to coordinate with medical staff is also the main reason for the cessation of hospital services ${ }^{13}$.

Successful disaster management is one that can withstand or even reduce the patient's mortality rate due to the disaster. The triage accuracy factor reduces mortality by $25 \%$ and decreases the cost of $12 \%$. The operating room's usage is following the indication of the patient. Therefore surgeons need to choose patients who need surgery ${ }^{14}$.

For hospitals to have a good system, disaster preparedness team needs to be formed to formulate the disaster management guidelines socialized to all hospital staff. The guidelines will improve staff responses to disasters ${ }^{14}$.

2. Level of Disaster Preparedness in Yogyakarta City Hospital

In supporting hospital disaster preparedness programs, the staff must have the training needed to be involved during a disaster. Training for medical and non-medical staff is needed to equalize staff's knowledge and ability in dealing with any scale of disaster ${ }^{15}$. Yogyakarta City Hospital has conducted training for its staff but only to some portions of the staff and not routinely conducted. The hospital also sends some of its staff to external K3 training (Occupational Health and Safety).

The training for medical staff, especially nurses, is essential because nurses are the first line in patients' evacuation on the care ward. Regular training can improve nurses' response to evacuation and actions when a disaster occurs ${ }^{16}$. Patients at the time of disaster are very vulnerable and need ongoing care, so that the first line that is swift in saving patients is a perfect strategy to prevent deaths in disasters ${ }^{17}$.

In the event of a disaster, hospital coordination was immediately carried out with the city government of Yogyakarta and the Regional Disaster Management Agency (BPBD). The hospital does not have a cooperative relationship with other health care networks.

The need for clean water supplies, food, consumables, medicines, and hospital linen for patients and employees can survive within 72 hours of a disaster. Also, there is still no agreements with local suppliers during the disaster.

The hospital room can be used for treatment rooms, and the lobby room can be set up as the maintenance ward. This situation was done in handling the victims of the mass disaster in the Bantul area earthquake in 2006. The maintenance ward located in the Azalea building had to be evacuated because it was located in a second and third-story building while the perinatal ward and delivery room were on the ground floor of the building.

Doctors and emergency care nurses carried out the victims' triage because all new patients were admitted from the ED. Locations and triage procedures already exist and are often tested, IGD personnel are already trained, and the resources for carrying out the triage follow the hospital's maximum capacity in a disaster situation.

3. Knowledge of Disaster Management Employees at Yogyakarta City Hospital

Knowledge is the underlying factor for nurses or other hospital staff to respond to disasters following disaster management guidelines. The Disaster Management Team and the K3 team need to ensure the level of staff knowledge about disasters in general and the guidelines implemented at the hospital18. Not all nurses and staff of Yogyakarta City Hospital got disaster training. Therefore their knowledge differs depending on how often they are involved with the program. This situation is what creates a distance between the staff's understanding and practice of disaster ${ }^{19}$.

The entire hospital response plan is contained in the disaster management book, but the book is not evenly distributed. This means that there is a lack of 
accessibility to disaster management guidelines for hospital employees. The guideline is often not updated, more than 12 months after the last update was made. Moreover, existing medical devices used during disasters and regulating procedures are not available at all times.

The disaster training in the Yogyakarta City Public Hospital can be categorized as Good (80\%). The training that was already held was PPGD training (Emergency First Aid) for emergency care nurses and fire extinguishers training. The training frequency is only once every few years, and only a few employees are sent to take part in external training. Training should still be held as an evaluation of future disaster preparedness. Training for all employees in the Yogyakarta City Public Hospital, both medical and non-medical, is needed to equalize staff's knowledge and ability in dealing with any scale of disaster ${ }^{15}$.

\section{CONCLUSION}

The results of the above research can be concluded that:

1. The hospital already has a Disaster Management Team called JHERT (Jogja Hospital Emergency Response Team) that acts as a quick reaction team for external disasters or handles internal hospital disasters. The disaster management plan is well documented in the Guide to Facilities and Security Management (MFK) of Yogyakarta City Hospital but has not yet been updated and resocialized since 2015 .

2. Observing and calculating Hospital Safety Index scores using 2015 WHO forms resulted in $62.5 \%$, thus included Yogyakarta City Hospital as a category B hospital. It indicates that the hospital still has risks when a disaster occurs to function optimally. They already have disaster policies but are not evaluated annually.

3. The score obtained from respondents filling out the knowledge questionnaire is $77 \%$. It indicates that their cognitive knowledge of disaster management is good.

\section{RECOMMENDATIONS}

1. Yogyakarta City Regional General Hospital Management needs to make revisions and improvements to the existing disaster management plan. Upon completion, the plan also should be routinely socialized to the staff.

2. JHERT should conduct routine training with a specific theme every few months for medical and non-medical staff to be part of the planned transition period. Nurses are the first line in handling the patients. Therefore they need to have training materials such as evacuation and handling of mass victims. Training for the JHERT should also be intensified by discussing how team members understood their job descriptions and their roles when disasters occurred.

3. All of the staff must participate in the training to have a better understanding and action towards disaster management. For the employee, the training includes evacuation, fire handling, and basic life support. For the management team, the training should be about creating a perfect hospital disaster plan.

4. Hospital Management should be more open with further research on disaster preparedness, thus, improving hospital shortcomings.

\section{ACKNOWLEDGMENT}

We thank Dr. Qurratul Aini, S.KG., M.Kes for assistance with methodology, writing, and comments that greatly improved the manuscript. We would also thank our colleagues from the Master of Hospital Administration program who provided insight and expertise that greatly assisted the research.

\section{REFFERENCES}

1. Skoufias, E., Strobl, E., Tveit, T., 2017. Natural disaster damage indices based on remotely sensed data: an application to indonesia, policy research working papers. The World Bank. https://doi.org/10.1596/1813-9450-8188

2. Nekoie-Moghadam, M., Kurland, L., Moosazadeh, M., Ingrassia, P.L., Della Corte, F., Djalali, A., 2016. Tools and checklists used for the evaluation of hospital disaster preparedness: a sistematic review. Disaster Med. Public Health Prep. 10, 781-788. https://doi.org/10.1017/dmp.2016.30

3. Heidaranlu, E., Ebadi, A., Khankeh, H.R., Ardalan, A., 2015. Hospital disaster preparedness tools: a sistematic review. PLoS Curr.

https://doi.org/10.1371/currents.dis.7a1ab3c8 9e4b433292851e349533fd77

4. Djalali, A., Carenzo, L., Ragazzoni, L., Azzaretto, M., Petrino, R., Della Corte, F., Ingrassia, P.L., 2014. Does hospital disaster preparedness predict response performance during a full-scale exercise? a pilot study. Prehospital Disaster Med. 29, 441-447. https://doi.org/10.1017/S1049023X1400082X

5. Toya, H., Skidmore, M., 2007. Economic 
development and the impacts of natural disasters. Econ. Lett. 94, 20-25. https://doi.org/10.1016/j.econlet.2006.06.020

6. Tang, R., Fitzgerald, G., Hou, X.-Y., Wu, Y.P., 2014. Building an evaluation instrument for china's hospital emergency preparedness: a sistematic review of preparedness instruments. Disaster Med. Public Health Prep. 8, 101-109. https://doi.org/10.1017/dmp.2014.10

7. Liu, B.F., Fowler, B.M., Roberts, H.A., Herovic, E., 2018. Keeping hospitals operating during disasters through crisis communication preparedness. Public Relat. Rev. 44, 585-597. https://doi.org/10.1016/j.pubrev.2018.06.002

8. Bin Shalhoub, A., Khan, A., Alaska, Y., 2017. Evaluation of disaster preparedness for mass casualty incidents in private hospitals in Central Saudi Arabia. Saudi Med. J. 38, 302306.

https://doi.org/10.15537/smj.2017.3.17483

9. Zarei, V., 2016. Emergency preparedness of hospitals in Tehran and its relation with crisis management measures 9

10. Voyer, J., Dean, M.D., Pickles, C.B., 2016. Hospital evacuation in disasters: uncovering the systemic leverage using system dynamics. Int. J. Emerg. Manag. 12, 152. https://doi.org/10.1504/IJEM.2016.076615

11. Kondo, H., Koido, Y., Morino, K., Homma, M., Otomo, Y., Yamamoto, Y., Henmi, H., 2009. Establishing disaster medical assistance teams in japan. Prehospital Disaster Med. 24, 556-564. https://doi.org/10.1017/S1049023X00007512

12. Basu, M., Ghosh, S., Jana, A., Bandyopadhyay, S., Singh, R., 2017. Resource mapping during a natural disaster: A case study on the 2015 Nepal earthquake. Int. J. Disaster Risk Reduct. 24, 24-31. https://doi.org/10.1016/j.ijdrr.2017.05.020

13. Janius, R., Abdan, K., Zulkaflli, Z.A., 2017. Development of a disaster action plan for hospitals in Malaysia pertaining to critical engineering infrastructure risk analysis. Int. J. Disaster Risk Reduct. 21, 168-175. https://doi.org/10.1016/j.ijdrr.2016.12.002

14. Russo, R.M., Galante, J.M., Jacoby, R.C., Shatz, D.V., 2015. Mass casualty disasters: who should run the show? J. Emerg. Med. 48, 685-692.

https://doi.org/10.1016/j.jemermed.2014.12.0 $\underline{69}$

15. Pham, P.K., Behar, S.M., Berg, B.M., Upperman, J.S., Nager, A.L., 2018. Pediatric Online disaster preparedness training for medical and non-medical personnel: a multilevel modeling analysis. Prehospital Disaster Med. 33, 349-354.
16. Pesiridis, T., Sourtzi, P., Galanis, P., Kalokairinou, A., 2015. Development, implementation and evaluation of a disaster training programme for nurses: A Switching Replications randomized controlled trial. Nurse Educ. Pract. 15, 63-67. https://doi.org/10.1016/j.nepr.2014.02.001

17. Tzeng, W.-C., Feng, H.-P., Cheng, W.-T., Lin, C.-H., Chiang, L.-C., Pai, L., Lee, C.-L., 2016. Readiness of hospital nurses for disaster responses in Taiwan: A cross-sectional study. Nurse Educ. Today 47, 37-42. https://doi.org/10.1016/j.nedt.2016.02.025

18. Ahayalimudin, N., Osman, N.N.S., 2016. Disaster management: Emergency nursing and medical personnel's knowledge, attitude and practices of the East Coast region hospitals of Malaysia. Australas. Emerg. Nurs. J. 203-209. https://doi.org/10.1016/j.aenj.2016.08.001

19. Yan, Y.E., Turale, S., Stone, T., Petrini, M., 2015. Disaster nursing skills, knowledge and attitudes required in earthquake relief: Implications for nursing education: Disaster nursing in earthquake relief. Int. Nurs. Rev. 62 , 351-359.

https://doi.org/10.1111/inr.12175 